"The Version of Record of this manuscript has been published and is available in The Senses and Society, 15(1), 70-84 ."

https://doi.org/10.1080/17458927.2019.1709301

\title{
Feeling the Unseen: Imagined Touch Perceptions in Paranormal Reality Television
}

Jarkko Toikkanen

University of Oulu \& Tampere University, Finland

jarkko.toikkanen@tuni.fi

https://orcid.org/0000-0002-7845-8615

\begin{abstract}
In paranormal reality television, the medial evidence of senses adding to the visual and auditory may produce the most compelling intermedial experience. When little can be seen or heard, the lasting impact of a ghost hunting show may rely on what it makes the audience feel through the sense of touch. Even if the touch perceptions were imagined - or precisely because they were imagined - the experience can be all the more powerful. Intermediality research supplies the rhetorical devices of ekphrasis and hypotyposis as tools for a study of the television show Ghost Adventures. A definition of senses as media is advanced in conjunction with a three-tier model of mediality to lay open the intermedial experience involved in imagined touch perceptions as medium-specific instances of rhetorical figuration.
\end{abstract}

\section{KEYWORDS}

Touch; intermedial experience; ekphrasis; hypotyposis; three-tier model of mediality; mediumspecificity; Ghost Adventures 


\section{Feeling the Unseen: Imagined Touch Perceptions in Paranormal Reality Television}

- PETE: When they go out and nothing happens, it's very disappointing.

PAULA: but I prefer that because that's more truthful. You can actually think, all right, fair enough, they've been waiting, nothing happened. You actually believe more. You are sitting there and watching that, waiting and anticipating, and nothing. Nothing, every time I watch it, nothing. PETE: If it's too exciting people don't believe. So it's quite difficult. They can't get a balance. (Hill 2011, 84)

- Hold on a second, man. I just felt, like, a jolt of electricity. I felt that vibrate through my whole body. That was weird!

(Zak Bagans)

Ghost hunting shows are one of the popular staples of paranormal reality television. The audience follows a group of people enter a building or location said to be haunted, and they watch as the lot attempts to secure proof of otherworldly activity by way of technology and collective experience. ${ }^{1}$ To many viewers, the premise can seem ridiculous and the broadcast show even more so because, quite routinely, nothing happens. People wander about in the dark, are jolted by something nobody else witnessed, and if something is caught on camera, it is a flash or noise that does not really prove anything. However, like Pete and Paula, the audience keeps coming back to these shows - they are "waiting for a haunting to happen" ("Retired female" quoted in Hill 2011, 77). What belies the expectation, and is it indeed so that nothing happens in the waiting? As Annette Hill says, in 
watching the viewers are "actively engaged in emotional, physical and psychological participation in a haunting atmosphere" $(2011,78)$, experiencing on the spot what to see and hear. Although they know they are watching a show and they are not present at the haunted location, the "sensory knowledge of hauntings" $(2011,86)$ mediated through the television screen keeps the audience engaged. But if nothing happens, what is the source of such knowledge?

I will argue that, in paranormal reality television, it may be the medial evidence of senses adding to the visual and auditory that produces the most compelling intermedial experience. When little can be seen or heard, the lasting impact of a ghost hunting show may rely on what it makes the audience feel and sense through the skin as one sensory perception turns into another. Affectively, even if the perception was wholly imagined - or precisely because it was imagined the experience can be all the more powerful and banish the need for shocking plot twists. As Hill puts it, "[i]n a reality TV show about ghosts an absence of drama can signify a haunting presence" $(2011,74)$ that, to fans like Pete and Paula, can appear as "more truthful" than an unbelievable spectacle that is "too exciting" to convince and hold them in anticipation.

I have selected two scenes from a single episode of Travel Channel's popular ghost hunting show Ghost Adventures (2008-) as my case material. As my aim is to show how imagined touch perceptions produce intermedial experience, the selection is based on both the peculiarity and commonality of these instances in the paranormal reality television environment. ${ }^{2}$ They are specific to the medium while, in recurring, they represent their genre and demand interpretation. The first element is vital, because just to claim that what one feels has interpretive value might sound trivial unless there was something else at stake. When what is there is not seen or heard but felt or, more peculiarly, imagined to be felt, how does that affect the intermedial experience? From the start, the format of Ghost Adventures was built on the generic premise of a three-man team of paranormal investigators spending a night (or two) in allegedly haunted places, recording evidence of strange occurrences by way of high-technology gadgets. The show's episodes would follow a template in 
which the investigators, led by Zak Bagans, first arrive at the scene, listen to first-hand testimonials of paranormal activity others have experienced at the same site, gather historical information that arguably supports the witnesses' stories, and finally set themselves up for a "lockdown" at the location. Whatever happens during the night - usually unexplained visual and auditory phenomena but haptic ones too ${ }^{3}-$ is instantly shared by the team on experiencing it, or it is captured by the audiovisual equipment, the data of which they will be able to analyze afterwards.

My main interest in Ghost Adventures does not involve the veracity of the paranormal activity recorded in the show, or any ghost hunting show, but how the medial sensory evidence on display produces intermedial experience that is described - and felt - as paranormal in the reality television environment. As sociological studies have indicated (e.g. Gordon 2008), whereas the cultural inclination towards new forms of spirituality in the 21 st century must have been a factor in the popularity of these shows and the plenitude of paranormal investigation teams all across the US, and with certain demographics responding especially well to them, I leave the discussion to others. ${ }^{4}$ Instead, in recognizing the recurring narrative of the program template, I will pay attention to the compelling intermedial moves and transformations that take place in Ghost Adventures, with the second-season episode Moon River Brewing Company (episode 7, Moon River from now on) as my example. The audience follows the crew as they visit the eponymous location in Savannah, Georgia. Having witnessed many historical battles, the town is identified by one of the locals as "the most haunted city in the United States", setting up the milieu as a properly eerie backdrop. The crew investigates, in the form of interviews, the history of the Moon River building, "the most haunted building" in Savannah. Built in the early 1800s, it has served different functions at various times in the past - from a hotel to vacant building and its current business as a brewery and bar with a reputation. As such, to borrow Hill's phrasing, it is furnished with "the atmosphere, temperature and visual features of a historic location" that "all contribute to the suggestion of a haunting" $(2011,78)$. 
Curiously, some of the most common paranormal experiences said to have been had within the premises involve child spirits, and no less than physical encounters between unearthly entities and patrons and staff. Here those members of the viewing audience who are familiar with the show will note a thematic connection that, in many of the episodes, links apparently innocuous manifestations such as child spirits with demonic forces. In ultimately building up to what is called "a partial possession" of one of the investigators, Nick Groff, Moon River is a prototypical example of the program template as it applies the supernatural theme and constructs its narrative around it. As the crew begins their lockdown, their minds are rife with the stories they have listened to, and the viewing audience is invited to interpret the data gathered during the night as evidence of the reliability of the stories. ${ }^{5}$ In this analysis, it is not my intention to explain every occurrence that takes place in the investigation, or to detail the show's entire script. I will focus on two key scenes in its design: 1) the lead investigator Bagans feeling an electric shock in the basement, and 2) a patron recalling being grabbed by the neck by an unseen entity in one of the rooms. Both instances have to do with imagined touch perceptions that, as I will claim, employ distinct types of rhetorical devices which may or may not demand interpretation to bring about intermedial experience.

The field of intermediality research has been as far and wide as the eye can see for at least two decades, ranging from a rich variety of conceptual definitions and neighboring notions to multiform analytical applications (e.g. Rippl 2015). Therefore, any exercise in intermediality that further plows the field must be philologically mapped, that is, by the relevant terms and their use. My experiment in this case provides a fresh application of the rhetorical device of ekphrasis that, to my knowledge and some occasional studies aside, has not been developed to accentuate touch. ${ }^{6}$ While there has been plenty of research on the cultural history and social aspects of touch, as well as the significance of touch in film studies (e.g. Marks 2000; Barker 2009; Classen 2012), the methodology employed in this article addresses a perceived lack and enables exciting intermedial 
developments in the rhetorical study of visual culture, the senses, and media research.

The use and understanding of ekphrasis has been expanding since the late 1990 from the definition ("the verbal representation of a visual representation") made popular by James W. Heffernan (1993) and W. J. T. Mitchell (1994) early in the decade. The direction was there in Claus Clüver's semiotic definition of ekphrasis as “the verbal representation of a real or fictitious text composed in a non-verbal sign system" $(1997,26)$. Tamar Yacobi articulated it most emphatically when she insisted on ekphrasis as a figure of speech that concerned not only artworks represented as a whole in another medium, but as identified in "instances" that came "down to a single element in a single work" found "in all genres of literature and in all modes of figuration" $(1997,35)$. In the case study to follow, sensory perceptions of touch are treated as instances of ekphrastic figuration.

To do so, what a medium is must be defined in a particular way too. In 2005 , Irina $\mathrm{O}$. Rajewsky included ekphrasis in the category of "intermedial references" that allude to and activate representations produced in one medium in another. ${ }^{7}$ The definition can be supported, but it must be stressed that my grasp of "medium" is not very common in intermediality research, as to me the term firstly refers to the basic sensory means by which we become aware of and perceive the environment - that is, experience what we conceive of as the surrounding world. In this fashion, ekphrastic figuration turns on the evidence of our senses, transitions between them - from sight to touch and everything in-between - and makes understanding possible. ${ }^{8}$ I call this whole process intermedial experience that is different in every instance yet adherent to the same medial logic and mechanism. At the same time, to avoid overgeneralizing ekphrasis and risk its ineffectiveness as an analytical tool, I will apply hypotyposis as the counterpart. Both are traditional rhetorical devices and about making the audience imagine sensory perceptions - visual images most commonly - but there is a special difference too. Hypotyposis was classically defined by Quintilian as the vivid description of a visual image, whereas the present-day understanding of ekphrasis involves medial representations of an artwork or instance in one medium represented in another medium. In this 
view, ekphrasis enforces the audience to interpret the representation (“what does it mean?"), whereas hypotyposis merely enforces the image (“how does it appear?”). (Toikkanen 2013; 2017.) It is a key distinction, the usefulness of which will become apparent in the analysis.

To operationalize the above definition of medium, I am launching a three-tier model of mediality. In everyday use, the plural term media does not refer to the basic sensory means, but also to the ways of presenting our perceptions of the environment in a variety of forms, consisting of works produced both in art and the everyday, in digital and non-digital designs. Therefore, the model is based on medium as a phenomenon which sets in and between sense perceptions and brings out the process of mediation on three levels. First, there are the basic sensory means of sight, hearing, touch, smell, and taste. Second, there are the ways of presenting sensory perceptions that may be simple (speech, writing, gesture) or complex (art forms and media formats). Third, there are the conceptual abstractions such as paranormal reality television as a cultural phenomenon or a ghost hunting show as a work of culture that draws on its environment. In this model, the first-tier sensory means are grasped as primarily mediating both what is imagined and what is not, whereas the second-tier ways of presenting mediate according to specific convention, and the third-tier conceptual abstractions mediate the ideas and judgments attached to the phenomena at hand.

This model - not crafted to be sequential but simultaneous - will be implemented in the case study to lay open the intermedial experience involved in sensory perceptions of touch as instances of ekphrastic and hypotypotic figuration. Past approaches, including Rajewsky's, have tended to favor the second tier, often with the purpose of classifying kinds of intermediality from a host of disciplinary perspectives, such as semiotics, interart studies and media research. In contrast, I propose to discover how the intermedial moves and transformations of Moon River fit the threetier model of mediality on all levels, what their rhetorical design is, and how the study relates to select theoretical counterpoints. John Guillory saw how the whole field of media studies still lacked an answer for "how to relate the theory of mediation to the fact of media" $(2010,359)$, or how 
explanations of the phenomenon of mediation fundamentally connected with the technological and institutional apparatuses known as media. Why and how exactly is it that media mediate?

In response, I will benefit from the theory of mediation informing the three-tier model of mediality, as it is combined with a close analysis of the case study to reveal its medium-specific rhetorical design. Doing so requires an update on the Modernist concept of medium-specificity as articulated by Clement Greenberg for whom it defined an art of painting that was free from the expression of medium-independent ideas and feelings that were able to traverse media without significant change. Greenberg focused on the affordances and limitations - "the irreduceable elements of experience" $(1940,303)$ - that were exclusive to painting and no other art: "It is by virtue of its medium that each art is unique and strictly itself." $(1940,305) .{ }^{9}$ Thus conceived, ekphrasis and hypotyposis belong in the realm of verbal art as they give rise to imaginary sensory perceptions that are medium-specific to reading literature or listening to an expert orator. However, as the rhetorical devices are employed in the study of another medium, such as paranormal reality television, they can yet be understood as producing effects that are medium-specific on the first tier of sensory perceptions even when they have moved, on the second tier, from literature or oratory to television. In this application, the Greenbergian concept is qualified, if not eradicated, because effect producing tools - rather than ideas and feelings - can traverse media while the irreducible experience of a specific medium remains. ${ }^{10}$ How do speech and gesture function in the paranormal reality television environment, and what kinds of imagined sensory perceptions do they give rise to?

As a further frame, parts of contemporary affect theory serve as a useful context for the conducted experiment on touch. Lisa Blackman's investigations are particularly useful both for her interest in Victorian spirituality, the influence of which is evident in today's ghost hunting shows, and for her unique take on affect theory. ${ }^{11}$ Whereas many theorists in the domain may seek to reduce the material body into sheer corporeal matter, Blackman attempts to preserve "the body's potential for psychic or psychological attunement" (2012, xxv). Here my question is, can the body 
be attuned to sense imagined touch perceptions, and if yes, how? In idealist philosophy, even though Kant dubbed touch "the most important and the most reliably instructive of all senses", it was "also the clumsiest" as the perceived object had to be "solid" and right there ([1798] 1996, 4142). Because sight and hearing could produce empirical knowledge of objects at a distance, they were the more privileged senses. In Kant's hierarchy, smell and taste constituted mere subjective accessories to the objective data provided by touch, sight and hearing that the thinking and feeling human being cognitively relied on. However, present-day affect theory on what constitutes one's senses and what kind of data one may gain from them have complicated the issue. If affect theorists such as Blackman are indeed right, and no a priori rational subject exists as the locus and source of human experience, the grasp of ekphrastic and hypotypotic figuration formed in one sensory medium moving and transforming into another could altogether change (cf. Gregg and Seigworth 2010; Wetherell 2012; Knudsen and Stage 2015). One has to be careful in reinventing idealist fundaments, but new knowledge may come out of it - particularly in the light of Kant's own preoccupation with hypotyposis as the linchpin between the literal and figurative presentation of sensory data (Toikkanen $2013 ; 2015) .^{12}$

To reiterate, the key point about Kant's aesthetics is that the sense of touch could not produce knowledge of objects that were not there. What is more, as non-imagined touch perceptions were immediate and fleeting, they did not linger as objects of contemplation, but were reacted to on the spot, akin to gustatory and olfactory sensations, after which they were gone. However, Mark Paterson $(2007,17)$ has claimed that when Aristotle, whose model Kant also draws on, describes the sense of touch in De Anima (On the Soul), the classical philosopher says something different:

Yet in the case of touch, our contact with things is erroneously perceived as direct, as unmediated. When perceiving textural qualities of roughness or smoothness, for example, in reality we perceive through an intermediary, our flesh and additionally 
our clothes, but simply fail to notice this. With tactility we are not affected or altered by the sense-object itself, nor simply through the medium (flesh), but actually in synchrony with the medium (423b).

Paterson highlights the fact that, for Aristotle, it is a mistake to think of touch perceptions as "direct" or "unmediated" sensations that were not cognitively mediated and could not function as objects of contemplation (cf. Heller-Roazen 2007). Because there is always flesh and clothes in the middle, the fact of which is neglected, the sensation only appears immediate whereas it is actually mediated in unison between what touches and what is being touched. The question is raised - flesh aside, what else can mediate touch? Can something that is not there be felt and contemplated on?

Another issue that must be raised regarding the sense of touch is the debate on how many senses human beings actually have, and what those senses are. The classical number going back to Aristotle is five - sight, hearing, touch, smell, and taste - but a long tradition of work in psychology and more recently in the neurosciences has suggested that somatic phenomena such as balance and body motion (proprioception) and even the stimulation of vital organs (interoception) should make the list too (cf. Howes 2009). ${ }^{13}$ Revising the three-tier model of mediality will be an ongoing task in this respect. What is more, with Ghost Adventures, it would be easy to slip into a discussion of sensory perceptual abilities commonly labelled as parapsychological or pathological, such as telepathy or the hearing of voices. However, as doing that would scatter the focus of the study at hand, and because theorists such as Blackman have already made convincing advances in this area, I refer the reader to them $(2001 ; 2008 ; 2015)$. In my analysis, I will only make use of the classical list of senses and explain the studied phenomena with their help.

Based on this premise, it will have to be shown how imagined touch perceptions produce intermedial experience, the production of which in the paranormal reality television environment can be studied through rhetorical methodology and the three-tier model of mediality. 
The important question is what goes into the making of any medial perception. As in Paterson's claim about the Aristotelian touch, there is the awareness of something being sensed and the grasp (that may be less than complete) of what is being sensed. The sensation and the perception are not separate from each other, either, as they meld into the experience of the moment - something is happening and it is made sense of. In effect, the "thing", or what may be called the object of the experience is presented and worked on. This object could be an idea about what the object represents (something "I" recognize and can interpret to a degree), about the agentive subject doing the work (how "I" am responding to the experience), or a combination of the two. In any case, the perception, imagined or non-imagined, is mediated by the sense or senses engaged, and an object of experience is required for the perception to exist at all. Indeed, such objects can be understood as objectified medial forms (or "images") that enable rhetorical figuration that brings about visual, auditory, or touch perceptions. ${ }^{14}$

Blackman's investigations can usefully elucidate this phenomenology. By developing new methods that would add to the "analytics of experimentation" available at the moment, her pronounced objective is "to construct a material-semiotic-affective apparatus that reorients perception toward new ways of seeing, hearing, listening, and feeling" (2015, 26-27). In much of her work, this aim has led to new insights about scientifically ambiguous phenomena such as telepathy and the hearing of voices, and her conclusions are never based on anything less than rigorous scrutiny that is often genealogical in nature. Consequently, her excursions into Victorian spirituality render a valuable source for its counterpart forms in the present, Ghost Adventures included. Blackman also resists the new materialistic tendencies of affect theorists like Brian Massumi who "draws a lineage with the work of William James and Henri Bergson to specify the importance of a vital force" but, by the same token, "silences their interest in psychopathology, hypnotic suggestibility and psychic phenomena that engendered this set of terms and concepts" $(2012,95)$. Massumi is seen as reducing affect to immediate functions of the body, located beyond 
the reach of awareness, when he examines too closely "the non-conscious and imperceptible vital force that traverses between and distributes human and non-human actors within a field of potential", and the role of the body is to provide "a 'conversion channel' or transducer that can modulate or amplify this intensive force through a kind of sensing feel, rather than a conscious calculation" $(2012,95)$. On her part, Blackman insists, quite to the contrary, on the "concept of mediated perception" to underscore the fact that "in order to engage in performative interpretation, one requires many eyes and ears, human and nonhuman, in order to make visible those entanglements that have become lost, separated, disjointed, and yet maintain an active absentpresence" $(2015,38$, emphasis in the original). In other words, while no Kantian rational subject may exist at the heart of human experience, there remains a mediating figure - a specific instance of rhetorical figuration - through and as which experience comes to be.

Ghost Adventures effectively makes use of this mechanism of intermedial experience in the paranormal reality television environment where different kinds of sensory perceptions, imagined and non-imagined, must be taken into account. Whose perception is being mediated at any moment, and whose experience is one making sense of? In the recurring narrative of the show, there are three positions to consider: the investigators, the witnesses interviewed, and the watching audience. In my analysis, the positions will come into play and be recognized in terms of the intermedial experience involved, the three-tier model of mediality proposed, and the mediumspecific rhetorical design at play. With such a design in place, the viewers' response need not be understood, as a cognitive scientific analysis might claim, as an empathetic simulation of someone else's reaction seen through the eye, but rather as a form of active participation in the show. ${ }^{15}$ It is a state of engagement with what we are shown and told, as well as made to wait for and feel.

In the second-tier television medium, the viewers engage the two Moon River scenes about to be analyzed through the first-tier media of sight and hearing, and understand them as part of the third- 
tier medium of Ghost Adventures. However, to stop at this conclusion would be to overlook much of the show's rhetorical design - just looking at and listening to the scenes is not sufficient in terms of active participation. A detached spectator will not feel the unseen, and no intermedial experience of the kind will come about. Therefore, the first-tier medium of touch is vitally important to the show's effect, and the imagined touch perceptions are presented in the paranormal reality television environment as mediating both the conventions of the second-tier television medium and the thirdtier ideas and judgments contextually attached to the supernatural and the Victorian influence.

Such is the orientation that informs the following analysis. To counter the objection that one cannot regulate audience reactions - that is, claiming it is impossible to know when the audience is going to feel X on seeing or hearing Y - I will benefit from W. J. T. Mitchell's method of "three phases or moments of realization" $(1994,152)$ in highlighting the functions of ekphrasis. Mitchell divides the audience's fascination with ekphrastic representation into three phases: indifference, hope, and fear. At first, ekphrastic indifference is the commonsense knowledge that an event or thing described in words can never have the same effect as the original event or thing, because the description is nothing but words. However, if one began to believe that the words were not just words, but a means of imaginatively re-enacting and connecting with what they represented, one would enter the phase of ekphrastic hope. Then again, should one linger in the imagination too long, one might become anxious over the potential consequences of such a connection - what if there was no way back or nothing was the same anymore? The third phase would be that of ekphrastic fear.

In the manner of Keats who is about to lose himself in the nightingale's song but at the last moment realizes the folly of his actions - Keats is writing his own song - the audience of Ghost Adventures might also feel they were being lured, by way of ekphrastic representation that engaged several senses, towards a frightful place where the very foundations of their reality were shaken. Then again, they might be indifferent and feel nothing of the sort. In either case, the medial 
logic and mechanism of intermedial experience remains the same. The audience member hopefully feeling along with the investigators only has an experience at odds with the audience member indifferently recognizing what they saw as contrived or even faked.

In the first Moon River scene analyzed, the lead investigator Bagans is struck by something unseen on the spot. Having arrived in situ, the team makes their way to the brewery and begins their interviews. One of the people is Murray Silver, a "5th-generation Savannahian", who, among other things, tells the team about a Catholic woman named Cristina Piva who was attacked by a supernatural entity on the premises:

MS: We publish a guidebook to haunted Savannah. The night that we had the rollout party here, the publisher, who is a good Catholic girl and doesn't believe in all of this crap, she was attacked physically.

ZB: Attacked?

MS: Attacked. Her family is so extremely Catholic, if you had mentioned - these people will tell you you're delirious. In fact, I've invited her here today to talk to you. ZB: She's here?

MS: Yeah, she's here. ${ }^{16}$

After the commercial break, the team go down to the basement where Silver is about to tell them more about the very area when Bagans experiences a strange sensation:

ZB: Hold on a second, man. I just felt, like, a jolt of electricity. I felt that vibrate through my whole body. That was weird! 
The watching audience's viewpoint at the moment is through Groff's camera who is filming Silver and Bagans as they speak. Once Bagans feels the "jolt of electricity", the camera cuts to the left where the third member of the team, Aaron Goodwin, is looking straight in the audience's direction with a facial expression that could be described as nervous excitement. The viewers, doubling as the holder of Groff's camera, are thereby invited to share in the experience and make sense of it.

How is the feeling of the unseen produced in this short scene? The audience watches as Bagans becomes aware of his body being affected, but he does not go on to interpret the jolt as anything or caused by anyone in particular. Since no explanation is given and no meaning assigned, the verbal representation of the "touch image" - the objectified medial form of rhetorical figuration - does not constitute an ekphrasis. Instead, as Bagans puts his sensation into words and calls it a jolt of electricity, he presents a verbal description that enforces the image in the form of a hypotyposis. In this way, for Bagans, the jolt does not have to do with immediate sensation but an object of experience to be described, and the situation is the same for his first-hand witnesses (Groff, Goodwin, and Silver) who are seen as reacting but not interpreting. The unexplained event functions as a hypotypotic cue that builds suspense and propels the show's narrative.

The audience responds according to what they have already learned about Bagans' experience in the bumper just before the commercial break, and also to the demand of interpreting the experience in the context of Ghost Adventures. They know it is not a home improvement show. In watching Bagans, the viewers reproduce the touch image produced by him - not in the sense of rationally inferring his state of mind, or feeling what he must have felt, but in the sense of becoming aware of a body being thus affected - and they link the image with its verbal description as a jolt of electricity. Now, if the audience was to stop there, at how Bagans appeared during the occurrence, they would not move beyond hypotyposis. However, as they try to make sense of the experience was it a ghostly spirit, overheated imagination, or was it faked? - they are invited to do so through Goodwin's eyes as Groff's camera. In this sense, the viewers' experience of the scene involves a 
representation of Bagans' experience, a partial interpretation of what it could mean. They might interpret the scene as something imagined or faked by Bagans (ekphrastic indifference), as proof of paranormal activity (ekphrastic hope), or as a threat to their sanity or world view (ekphrastic fear). In each instance, the medial logic and mechanism of intermedial experience remains the same, and, as the three-tier model of mediality would suggest, the first-tier perception is medium-specifically about touch - not real but imagined - even though the third-tier program in the second-tier television medium continues to depend on sight and hearing.

In such a rhetorical design, audience response should not be reduced into unintentional mimicry as members become active participants who can be made to feel the unseen. In presenting the viewers with the sudden vibrations affecting Bagans' body, the scene enforces them to imagine the vibrations simply because they are presented. It is like being asked to imagine zero ghosts - it cannot be done for the reason that the image of a ghost is produced automatically. (For a becoming analogy, recall the "choose the form of the destructor" scene at the end of the original Ghostbusters movie.) This phenomenology of automatic production corresponds with the concept of automatism Blackman has referred to "as the sense one might have of being governed by imperceptible forces compelling one to act beyond one's control" $(2012,72) .{ }^{17}$ Even if there was nothing mysterious or bizarre about the source of experience, or the shock was due to faulty wiring, the production of medial images could not be prevented or regulated. Such images can as much involve the sense of touch as they can sight and hearing. Whether the viewers feel the jolt of electricity exactly like Bagans is irrelevant, as they only need to be presented with the hypotypotic touch image to engage their sense of touch in the form of an imagined touch perception. Following the cue, as the audience makes sense of their experience, choosing from a set of interpretations, they produce what can be called a haptic ekphrasis, the verbal representation (viewers' interpretation) of a representation in another medium (Bagans' electric shock). Enacting Blackman's concept of mediated perception beyond Kantian idealism, what they imagine and understand become 
mediating figures - specific instances of rhetorical figuration - through and as which intermedial experience comes to be.

In the second Moon River scene, the team meets with Cristina Piva, who has gathered the courage to return to the place of her paranormal encounter. A dialogue takes place:

ZB: Okay, we're here with Cristina right now, and, Cristina, did something happen to you during this party?

CP: Well, we had energy that was not of flesh and bones, I can tell you. It was really weird. I was coming down that hallway. I was alone, and I came to this back room, was right here. When I got to here, as if, like this was a physical presence on my neck, thrown back, back, pushing me back. I was choking and coughing. I could not breathe. ZB: Kind of grab you by the neck, like, "don't come in here"?

CP: I did not cross this threshold. I don't believe in this stuff. I mean, I did not believe in this stuff.

ZB: You believe now?

CP: Oh, my gosh. I mean, I get the goose bumps just talking about it. It's so vivid.

During the scene, the camera stays focused on Piva and Bagans so there is no audience participation effect in the same way as in the previous scene. The weight of the interpretation is squarely placed on Piva's experience as she recalls how it originally took place, retracing some of her moves and reenacting the described "physical presence" on her own body, as well as Bagans', by pretending to grab him by the neck. In this fashion, the audience is not primarily invited to imagine being grabbed themselves but to imagine what it must have felt like for Piva at the moment of the encounter. 
How does this scene involve either a hypotyposis or ekphrasis or both? On the one hand, the sensation of being touched (or violently grabbed) on the skin is different from getting one's body struck by an unseen elemental force because it invites a set of interpretations that, in this case, have to do with ghostly or demonic entities. In her experience of being "thrown back" and not being able to breathe, Piva's whole body is affected by the occurrence, but arguably the triggering touch image is that of being touched on the skin. The image is hypotypotic (imagined first-tier touch perception) only as long as no meaning is assigned to it - as was the case with the jolt of electricity - but it turns ekphrastic once the source is understood to possess human resemblance.

On the other hand, since the experience described is in the past, the touch image reproduced by Piva in the interview has to do with a representation rather than a presentation. Whereas Bagans becomes aware of what is happening in the instant, and goes on to describe it in the form of a hypotyposis, Piva turns into her own audience and tries to make sense of her past experience by endeavoring to interpret it. In the process, she produces a haptic ekphrasis, the verbal representation (present interpretation of her past experience) of a representation in another medium (Piva being grabbed by an entity). As she re-enacts the past action by pretending to grab Bagans, she complements her words by gestures to add to the second-tier performance. Holding on to the routine of ghost hunting shows, neither Piva nor the investigators eventually conclude in any definitive interpretation of allegedly paranormal activity - which she refers to as "this stuff" in the dialogue - but the medial logic and mechanism of intermedial experience is more than enough to maintain its affective power, as evidenced by the "goose bumps" she feels in the present as the audience to her own story ("It's so vivid.").

From the viewers' position, devoid of literal touch, the sensation of being grabbed by the neck or getting the goose bumps are readily as imaginable, and just as effective as hypotypotic touch images, as the jolt of electricity. In the three-tier model of mediality, the first-tier perception has to do medium-specifically with touch even if the second-tier television medium, dependent on 
sight and hearing, was unaltered in the third-tier medium of Ghost Adventures. However, what is different between the two scenes is the function of the ekphrastic device. In the first instance, the watching audience is invited to share in the experience and make sense of it because nobody in the program will so do. Do ghosts really exist, or is it for the show? The viewer may interpret the scene indifferently, hopefully, or, in the worst case scenario, as a threat to their sanity or world view. In contrast, in the second instance, the spotlight is on Piva. The first-hand witness becomes her own audience, and the viewers will gauge her credibility as opposed to believing, or disbelieving, in the supernatural themselves. She might think that ghosts, or maybe demons, exist, but the audience is not obligated to make up their minds about the matter. Paranormal reality television thrives on this ambiguity, and the shows base their popularity on how well they can maintain it. In the case of Ghost Adventures, now running in its 17 th season, the success has been obvious. As long as it is possible to feel the unseen, we will wait and anticipate, also when nothing is seen or heard.

\section{Notes}

1. The first shows to gain success were Most Haunted (UK, 2002-2010, 2013-) and Ghost Hunters (US, 2004-2016, 2019-).

2. To my knowledge, there are no other studies to have focused with a rhetorical methodology on the intermedial experience of imagined touch perceptions. The selection of scenes for analysis is limited for a purpose, as it best helps to demonstrate the method used and leaves the option open for further research and application. In joining the field of intermediality research with multidisciplinary sensory studies, one avenue would be to explore the potential kinship between the three-tier model of mediality developed in this article and the concept of intersensoriality advanced, among others, by Steven Connor (2004), David Howes (2004), and Mark M. Smith (2007), after Michel Serres.

3. My use of "haptic" in referring to the sense of touch follows Mark Paterson who derives it from Aristotle and defines "haptic" as "[r]elating to the sense of touch in all its forms", subdividing "proprioception", "vestibular", "kinaesthesia", "cutaneous", "tactile", and "force feedback" under it 
(2007, ix). What is more, this article could potentially contribute to haptic media studies - and the "haptic moment" of our contemporary media environment - endorsed by David Parisi, Paterson, and Jason Edward Archer (2017).

4. Marc A. Eaton has noted that "over 3,000 paranormal investigation teams exist in the United States, and more exist worldwide" $(2015,389)$. The interest in ghost belief is linked to diminishing "confidence in organized religion" that, in turn, is identified as the result of a general shift "toward individualized modes of belief and practice" $(2015,389)$. In the US, the commonly met paranormal investigator suggested by Eaton's study is white and Catholic. For related research in experimental parapsychology, see Childs and Murray (2010), and, for a history of paranormal beliefs in relation to media and communication technologies since the 19th century in the US, see Sconce (2000).

5. A common method of ghost hunting shows to dispel audience doubt is for the investigators to assume a discursive position that Peter Lamont (2007) has titled as "avowal of prior skepticism". Doing so is supposed to prevent the audience from considering them as biased or gullible from the start - indeed, the opening sequence of Ghost Adventures begins with Bagans narrating: "I never believed in ghosts until I came face to face with one".

6. Courtney Roby has used the ekphrastic description of a boxing match in Apollonius' Argonautica as an example of "tactile engagement" that "the reader cannot help but feel in sympathy, like chattering teeth and snapping bones" (2016, 115). Cecilia Lindhé (2017) has developed the notions of visual touch and digital ekphrasis. Horea Avram and Claudiu Turcus (2014) edited a special issue of Ekphrasis: Images, Cinema, Theory, Media on the haptic and corporeal.

7. As Gabriele Rippl clarifies the scope of intermediality research in her introduction to Handbook of Intermediality, she refers to Werner Wolf, Jens Schröter, and Lars Elleström as authorities in the field today who, with Rajewsky, "have presented definitions and typologies which help to differentiate a wide range of intermedial phenomena" $(2015,11)$.

8. This definition of medium draws on Aristotelian thought, and I will return to it in discussing the fleetingness of touch perceptions (e.g. Classen 1993; Nichols, Kablitz, and Calhoun 2008; Jensen 2011). The definition also resembles Marshall McLuhan's (1964) idea of media as "extensions" of ourselves. However, unlike McLuhan, I do not consider media only as vehicles of information we 
process to change our way of thinking, because such an idea of media as sheer data reduces them into semiotic modes of information that dissolve the sensory perception.

9. Accessed 10 December 2019 at

http://www.bu.edu/partisanreview/books/PR1940V7N4/HTML/files/assets/basic$\underline{\text { html/index.html\#296. }}$

10. In the 2000s, Greenbergian views have been replaced in art studies, among other things, with how medium-specificity should be understood, after Barthes, as "a function of the structures of intention underwriting a given practice" (Costello 2008, 311), or, after McLuhan, as an embodied experience in which "our senses are instrumentalized" so that "we are joined to the sensory tools we have made to amplify and accompany the self' (Jones 2006, 17). Whereas Greenberg's essentialism about the unique qualities of the arts is gone, media now appear as practical functions and tools for use.

11. As the theoretical and methodological focus of this article is on intermediality research and contemporary affect theory, the extent to which relevant historical and philosophical considerations can be included is limited in scope. For more on the development of influential connections from the 19th century to the present day, see Fisher (2007), and Blackman (2012). For more on the cultural history of the senses, see Classen (2012), Howes and Classen (2013), as well as Bloomsbury's ongoing series A Cultural History of the Senses.

12. In the Critique of Pure Reason, Kant divides "schematic hypotyposis" from "symbolic hypotyposis" with the former denoting a direct, literal connection between sensory data and its presentation in words, whereas the latter expresses a roundabout, figurative connection. Paul de Man has argued the division is precarious at best.

13. See John F. Kihlström's extensive online materials (“Sensation”, Psychology: The Science of Mind and Behavior) at the University of California, Berkeley, accessed 10 December 2019 at https://www.ocf.berkeley.edu/ jfkihlstrom/IntroductionWeb/sensation supplement.htm.

14. Annette Hill says Laura Marks' concept of haptic visuality "combines vision with touch to explain a mixed mode of engagement" $(2011,102)$. However, in Marks' own definition of the concept, "the eyes themselves function like organs of touch" $(2000,162)$. Imagined touch perceptions are thus 
seen as miming non-imagined visual perceptions they service transmedially. Touch acts a nonmedium-specific source of visual content (“see what you feel”).

15. Emily T. Troscianko explains cognitive simulation theory as "mind-reading" that "happens by means of a simulation of the other person's actions, followed by a simulated experience of the mental state which gave rise to those actions, and a subsequent attribution of this mental state to the other person" $(2014,174)$.

16. The transcript is based on the text accessed 10 December 2019 at http://www.allreadable.com/19ba6yUz. For improved accuracy, any deviations from the online source are mine.

17. Groff's "partial possession" at the end of the episode, a common convention of ghost hunting shows, could be seen as the epitome of such loss of control, faked or not, as represented in the program.

\section{Acknowledgements}

This article was completed with support from the Finnish Cultural Foundation and the Academy of Finland (project number 285144, "The Literary in Life: Exploring the Boundaries between Literature and the Everyday"). I wish to thank the anonymous reviewers appointed by The Senses and Society for their insight in completing my contribution.

\section{Disclosure statement}

No potential conflict of interest was reported by the author.

\section{Notes on contributor}

Jarkko Toikkanen is Senior Lecturer in English at the University of Oulu, Finland, and Adjunct Professor at Tampere University, Finland. His research is focused on the concept of intermedial experience, or how experiencing literature and other media produces sensory perceptions, both 
imagined and non-imagined, through medium-specific ways of presenting that mediate the conceptual abstractions of language and culture. This three-tier model of mediality is a work in progress. Toikkanen has published articles on Wordsworth and Poe, among others, the monograph The Intermedial Experience of Horror: Suspended Failures (Palgrave Macmillan, 2013), and two co-edited anthologies including The Grotesque and the Unnatural (Cambria Press, 2011).

\section{References}

Avram, H., and C. Turcus, eds 2014. Ekphrasis: Images, Cinema, Theory, Media 12 (2). doi:10.24193/ekphrasis.

Barker, J.M. 2009. The Tactile Eye: Touch and the Cinematic Experience. Berkeley: University of California Press.

Blackman, L. 2015. "Researching Affect and Embodied Hauntologies: Exploring an Analytics of Experimentation." In Affective Methodologies: Developing Cultural Research Strategies for the Study of Affect, edited by B.T. Knudsen, and C. Stage, 25-44. Basingstoke: Palgrave Macmillan. doi:10.1057/9781137483195_2.

Blackman, L. 2012. Immaterial Bodies: Affect, Embodiment, Mediation. Los Angeles: SAGE. doi: $10.4135 / 9781446288153$.

Blackman, L. 2008. The Body: The Key Concepts. Oxford and New York: Berg.

Blackman, L. 2001. Hearing Voices: Embodiment and Experience. London: Free Association Books.

Childs, C., and C.D. Murray. 2010. "“We All Had an Experience in There Together:' A Discursive Psychological Analysis of Collaborative Paranormal Accounts by Paranormal Investigation Team Members." Qualitative Research in Psychology 7 (1): 21-33. doi:10.1080/14780880903304543. 
Classen, C. 2012. The Deepest Sense: A Cultural History of Touch. Champaign: University of Illinois Press. doi:10.5406/illinois/9780252034930.001.0001.

Classen, C. 1993. Worlds of Sense: Exploring the Senses in History and Across History. London: Routledge.

Clüver, C. 1997. “Ekphrasis Reconsidered: On Verbal Representations of Non-Verbal Texts.” In Interart Poetics: Essays on the Interrelations of the Arts and Media, edited by U.-B. Lagerroth, H. Lund, and E. Hedling, 19-33. Amsterdam: Rodopi.

Connor, S. 2004. "Edison's Teeth; Touching Hearing.” In Hearing Cultures: Essays on Sound, Listening, and Modernity, edited by V. Erlmann, 153-172. Oxford and New York: Berg. doi: $\underline{10.5040 / 9781474214865 . c h-008 .}$.

Costello, D. 2008 “On the very idea of a 'specific' medium: Michael Fried and Stanley Cavell on painting and photography as arts". Critical Inquiry 34 (2): 274-312. doi:10.1086/529058.

Eaton, M.A. 2015. ““Give us a Sign of Your Presence:' Paranormal Investigation as a Spiritual Practice.” Sociology of Religion 76 (4): 389-412. doi:10.1093/socrel/srv031.

Fisher, J., ed. 2007. Technologies of Intuition. Toronto: Y Y Z Books.

Gordon, A.F. 2008. Ghostly Matters: Haunting and the Sociological Imagination. Minneapolis: University of Minnesota Press.

Greenberg, C. 1940. “Towards a Newer Laocoön.” Partisan Review 7 (4): 296-310.

Gregg, M., and G.J. Seigworth, eds 2010. The Affect Theory Reader. Durham: Duke University Press. doi: $10.1215 / 9780822393047$.

Guillory, J. 2010. “Genesis of the Media Concept.” Critical Inquiry 36 (2): 321-362. doi: $10.1086 / 648528$.

Heffernan, J.A.W. 1993. Museum of Words: The Poetics of Ekphrasis from Homer to Ashbery. Chicago: The University of Chicago Press. 
Heller-Roazen, D. 2007. The Inner Touch: Archaeology of a Sensation. Brooklyn: Zone Books. Hill, A. 2011. Paranormal Media: Audiences, Spirits and Magic in Popular Culture. London: Routledge. doi:10.4324/9780203836392.

Howes, D., ed. 2009. The Sixth Sense Reader. Oxford: Berg.

Howes, D., ed. 2004. Empire of the Senses: The Sensual Culture Reader. Oxford: Berg.

Howes, D. and C. Classen. 2013. Ways of Sensing: Understanding the Senses in Society. Oxon and New York: Routledge. doi:10.4324/9781315856032.

Jensen, K.B., ed. 2011. A Handbook of Media and Communication Research: Qualitative and Quantitative Methodologies. Second edition. Abingdon: Routledge. doi:10.4324/9780203357255. Jones, C.A. 2006. “The Mediated Sensorium.” In Sensorium: Embodied experience, technology, and contemporary art, edited by C.A. Jones, 5-49. Cambridge: The MIT Press.

Kant, I. [1798] 1996. Anthropology from a Pragmatic Point of View. Trans. V.L. Dowdell. Revised and edited by H.H. Rudnick. Carbondale: Southern Illinois University Press.

Knudsen, B.T., and C. Stage, eds 2015. Affective Methodologies: Developing Cultural Research Strategies for the Study of Affect. Basingstoke: Palgrave Macmillan. doi:10.1057/9781137483195. Lamont, P. 2007. "Paranormal Belief and the Avowal of Prior Scepticism." Theory and Psychology 17 (5): 681-696. doi:10.1177/0959354307081624.

Lindhé, C. 2017. "Visual Touch. Ekphrasis and Interactive Art Installations." In Museums in a Digital Culture: How Art and Heritage Become Meaningful, edited by C. van den Akker, and S. Legêne, 31-40. Amsterdam: Amsterdam University Press. doi:10.1515/9789048524808-004. Marks, L.U. 2000. The Skin of the Film: Intercultural Cinema, Embodiment, and the Senses. Durham: Duke University Press. doi:10.1215/9780822381372.

McLuhan, M. 1964. Understanding Media: The Extensions of Man. London and New York: McGraw-Hill. 
Mitchell, W.J.T. 1994. Picture Theory. Chicago: The University of Chicago Press.

Nichols, S.G., A. Kablitz, and A. Calhoun, eds 2008. Rethinking the Medieval Senses: Heritage Fascinations Frames. Baltimore: Johns Hopkins University Press.

Parisi, D., M. Paterson, and J.E. Archer. 2017. “Haptic Media Studies.” New Media \& Society 19 (10): 1513-1522. doi:10.1177/1461444817717518.

Paterson, M. 2007. The Senses of Touch: Haptics, Affects and Technologies. Oxford: Berg. doi: $10.5040 / 9781474215831$.

Rajewsky, I.O. 2005. “Intermediality, Intertextuality, and Remediation: A Literary Perspective on Intermediality." Intermédialités 6: 43-64. doi:10.7202/1005505ar.

Rippl, G., ed. 2015. Handbook of Intermediality: Literature - Image - Sound - Music. Berlin: Walter de Gruyter. doi:10.1515/9783110311075.

Roby, C. 2016. Technical Ekphrasis in Greek and Roman Science and Literature: The Written Machine between Alexandria and Rome. Cambridge: Cambridge University Press. doi: $10.1017 /$ cbo9781139924849.

Sconce, J. 2000. Haunted Media: Electronic Presence from Telegraphy to Television. Durham \& London: Duke University Press.

Smith, M.M. 2007. Sensing the Past: Seeing, Hearing, Smelling, Tasting and Touching in History. Berkeley: University of California Press.

Toikkanen J. 2017. “Auditory Images in Edgar Allan Poe's 'The Tell-Tale Heart'.” The Edgar Allan Poe Review, 18 (1): 39-53. doi:10.5325/edgallpoerev.18.1.0039.

Toikkanen J. 2015. “Transcendental Puppets: Kant and Kleist.” In The Poetics of Transcendence, edited by E. Heinämäki, P.M. Mehtonen and A. Salminen, 159-178. Amsterdam: Brill Rodopi. doi:10.1163/9789401212090_009. 
Toikkanen J. 2013. The Intermedial Experience of Horror: Suspended Failures. Basingstoke:

Palgrave Macmillan. doi:10.1057/9781137299093.

Troscianko, E.T. 2014. Kafka's Cognitive Realism. New York: Routledge.

doi: $\underline{10.4324 / 9780203082591 .}$.

Wetherell, M. 2012. Affect and Emotion. London: SAGE.

Yacobi, T. 1997. "Verbal Frames and Ekphrastic Figuration.” In Interart Poetics: Essays on the

Interrelations of the Arts and Media, edited by U.-B. Lagerroth, H. Lund, and E. Hedling, 19-33.

Amsterdam: Rodopi. 